\title{
ОРГАНІЗАЦІЯ ВІДБОРУ В СЕКЦІЮ КІОКУШИНКАЙ КАРАТЕ
}

\author{
Софія Мухіна ${ }^{1 \mathrm{ABCD}}$, Світлана Марченко ${ }^{1 \mathrm{ABCD}}$ \\ ${ }^{1}$ Харківський національний педагогічний університет імені Г. С. Сковороди
}

Authors' Contribution: A - Study design; B - Data collection; C - Statistical analysis; D - Manuscript Preparation; E - Funds Collection

DOI: $10.17309 /$ jltm.2021.1.05

\begin{abstract}
Анотація
Мета дослідження - визначити факторну модель морфофункціональної та рухової підготовленості хлопців 8 років на етапі початкового відбору до спортивної секції кіокушинкай карате.

Матеріали і методи. У дослідженні взяли участь 32 хлопці 8 років. Діти та їхні батьки були інформовані про всі особливості дослідження і дали згоду на участь в експерименті. Для вирішення поставлених завдань були використані методи дослідження: теоретичного аналізу і узагальнення даних науково-методичної літератури; педагогічного спостереження; хронометражу навчальних завдань; педагогічного тестування; методи математико-статистичної обробки даних.

Результати. Отримана факторна модель комплексної оцінки перспективності хлопців 8 років у процесі відбору на початковому етапі спортивної підготовки. У результаті аналізу кореляційної залежності між тестовими завданнями встановлено їх високу інформативність. Пріоритетне місце у факторній структурі займають антропометричні показники та процеси розвитку швидкісних, швидкісно-силових та координаційних здібностей.

Висновки. Найбільшу інформативність для комплексної оцінки перспективності дітей під час відбору для занять у спортивній секції карате мають результати тестів: «Біг 30 метрів з високого старту» $(0,889)$, «Стрибок у довжину з місця» $(0,748)$, «Окружність грудей» $(0,839)$, «Маса тіла» $(0,801)$, «Стійка на одній нозі з закритими очима» $(0,834)$, «Ходьба по прямій лінії після 5 обертів» $(0,855)$.

Ключові слова: хлопці, відбір, морфофункціональна підготовленість, рухова підготовленість, факторний аналіз, карате.
\end{abstract}

\section{Вступ}

Початок XXI століття характеризується підвищеним інтересом вчених до проблеми прогнозування (Den Hartigh, R. J. R., Niessen, A. S. M., Frencken, W. G. P., \& Meijer, R. R., 2018; Ivashchenko, 2020) у різноманітних областях наукових знань. Звісно це питання не залишилося в стороні від фізичної культури (Khudolii, Ivashchenko, Iermakov, Nosko, \& Marchenko, 2019; Марченко \& Коваленко, 2020).

Це обумовлено рядом багатьох причин, основними 3 яких є: стрімке підвищення значущості спорту в соціальному і політичному житті суспільства, створення позитивних моделей поведінки і формування моральних цінностей (Cynarski, 2019; Cynarski, \& Niewczas, 2019; Augustovicova, Argajova, Rupcik, \& Thomson, 2020), необхідність пошуку інновацій в підготовці кваліфікованих спортсменів вищої кваліфікації до найважливіших міжнародних змагань, розробка новітніх методів дослідження рухової та фізичної підготовленості, тренувальних

(c) Mukhina, S. \& Marchenko, S., 2021. і змагальних навантажень (Platonov, 2018; Ivashchenko, Iermakov, \& Khudolii, 2021).

Разом 3 тим пандемія, малорухливий спосіб життя, дистанційне навчання створили всі умови для зниження рухової активності молоді та погіршення стану здоров'я дітей. Суспільство занепокоєне таким перебігом подій. Відповідно ситуація, яка склалася, вимагає кардинальних змін та модернізації підходів до розвитку та популяризації фізичної культури учнів та учнівського спорту.

Саме тому Міністерство освіти і науки України видало наказ № 194 від 15.02.2021 року «Про затвердження Рекомендацій щодо стратегічного розвитку фізичного виховання та спортивної підготовки серед учнівської молоді на період до 2025 року».

Згідно з документом, результати щорічного оцінювання фізичної підготовленості населення, показали, що у 2018/2019 навчальному році недостатній рівень фізичної підготовленості мали 65,1 \% учнів. Спостерігалось зниження рухової активності молоді й протягом 2019/2020 навчального року, а через введення карантинних заходів спричинених значним поширенням COVID-19 у 2020 році ситуація ускладнилась. 
У тексті Наказу вказано, що основними видами фізичного виховання у закладах освіти є уроки фізичної культури, що спрямовані на розвиток здоров'язбережувальної компетентності, стійкої мотивації здобувачів освіти до занять фізичною культурою і спортом, та інші види заняття з фізичного виховання та спортивної підготовки.

Слід зазначити, що проблема спортивної орієнтації і відбору ще до кінця не вирішена і вимагає подальшого осмислення як ученими, так і практиками. Все це зумовлює актуальність і доцільність розробки теми: «Організація відбору в секцію кіокушинкай карате».

Мета дослідження - визначити факторну модель морфофункціональної та рухової підготовленості хлопців 8 років на етапі початкового відбору до спортивної секції кіокушинкай карате.

\section{Матеріали і методи}

\section{Учасники дослідження}

У дослідженні взяли участь 32 хлопці 8 років. Діти та їхні батьки були інформовані про всі особливості дослідження і дали згоду на участь в експерименті.

\section{Організація дослідження}

Для вирішення поставлених завдань були використані методи дослідження: теоретичного аналізу і узагальнення даних науково-методичної літератури; педагогічного спостереження; хронометражу навчальних завдань; педагогічного тестування; методи математикостатистичної обробки даних.

Основою у плануванні дослідження стали концептуальні підходи до розробки програми наукових досліджень у фізичному вихованні і спорті (Ашмарин, 1978; Круцевич, 1985; Худолій \& Іващенко, 2004).

Обрані методи дозволяють своєчасно аналізувати фізичний стан дітей, прогнозувати їх готовність до участі у тестуванні. Корегувати програми відбору та у подальшому спланувати навчальний процес.

Для оцінки фізичного розвитку проводили антропометричне обстеження із дотриманням основних вимог уніфікованої методики антропометричних досліджень, розробленої Бунаком (1941). Вивчали 5 показників. Визначали масу тіла, довжину тіла, окружність грудної клітини, життєву ємність легень, динамометрію правої та лівої рук.

У програму тестування рухової підготовленості ввійшли загальновідомі тести (Марченко, 2007; Сергієнко, 2010; Марченко \& Безпалько, 2020): біг 30 метрів з високого старту, біг 300 метрів, нахил тулуба вперед із положення сидячи, підтягування у змішаному висі на канаті, стрибок у довжину з місця, човниковий біг $4 \times 9$ метрів, вправи на поєднання рухів руками, тулубом і ногами, стійка на одній нозі з закритими очима, ходьба по прямій лінії після 5 обертів. Тести підбиралися таким чином, щоб усебічно охарактеризувати структуру рухової підготовленості дітей.

\section{Статистичний аналіз}

У дослідженні використовувалася програма - IBM SPSS 26. Обчислювались такі параметри: середнє ариф- метичне значення величини (M), стандартне квадратичне відхилення, яке характеризує мінливість ознаки (SD). Для оцінки тісноти взаємозв'язку між параметрами розраховувався коефіцієнт кореляції Пірсона. Для узагальнення та скорочення кількості змінних і об’єднання їх у групи на основі характерних зав'язків використовувався факторний аналіз. У процесі проведення факторного аналізу розраховували та аналізували наступні показники: критерій сферичності Бартлетта, КМО - міра адекватності вибірки Кайзера-Мєйєра-Олкіна. Виділення факторів було проведено методом головних компонент (АГК), Обертання факторів виконувалось методом «Варімакс» 3 нормалізацією Кайзера.

\section{Результати}

Дослідження ефективності експериментального плану оцінки перспективності дітей проводилася на основі комплексу показників, що відображають готовність школярів до занять в секції кіокушинкай карате в позаурочний час. Результати дослідження наведені в таблицях 1-4.

Показники досліджуваних дітей характеризують рівень прояву в них рухових здібностей та антропометричних показників. Аналіз середньостатистичних показників тестування показує, що загалом за усіма тестами більшість показників відповідають закону нормального розподілу.

Критерій сферичності Бартлетта вказує на те, що отримані нами дані цілком прийнятні для проведення факторного аналізу при рівні значущості $\mathrm{p}<0,05$. Розрахований нами критерій Кайзера-Мєйєра-Олкіна характеризує задовільну адекватність використання факторного аналізу до цієї вибірки 0,603 (табл. 1).

Таблиця 1. Перевірка доцільності використання факторного аналізу

\begin{tabular}{lll}
\hline \multicolumn{3}{c}{ КМО і критерій Бартлетта } \\
Міра адекватності вибірки & $\mathbf{0 , 6 0 3}$ \\
Кайзера-Мєйєра-Олкіна (КМО) & \\
\hline Критерій сферичності & Приблизний Хі-квадрат & 280,866 \\
Бартлетта & ст.св. & 105 \\
& Значимість & 0,000 \\
\hline
\end{tabular}

У таблиці 2 наочно представлена кореляційна матриця яка включає в себе усі можливі коефіцієнти кореляцій (r) між змінними, що аналізуються. Коефіцієнти кореляції характеризують щільність зв’язку між змінними початкового масиву даних.

Достовірна ступінь кореляційного зв'язку виявлена у «Бігу 30 метрів з високого старту» з тестами «Біг 300 метрів» $(\mathrm{r}=, 799)$, «Стрибок у довжину з місця» $(\mathrm{r}=$ $-0,754)$, «Човниковий біг $4 \times 9$ метрів» $(\mathrm{r}=0,566)$ та «Ходьба по прямій лінії після 5 обертів» $(\mathrm{r}=0,515)$.

Спостерігається тісний взаємозв'язок між результатами тесту, який характеризує загальну витривалість з тестами на здібність до диференціювання просторово-часових параметрів рухів $(\mathrm{r}=0,478)$ та здібність до швидкісно-силової роботи $(\mathrm{r}=-0,576)$.

На рівні середнього ступеня значимості корелюють показники силових здібностей зі здібністю до збережен- 


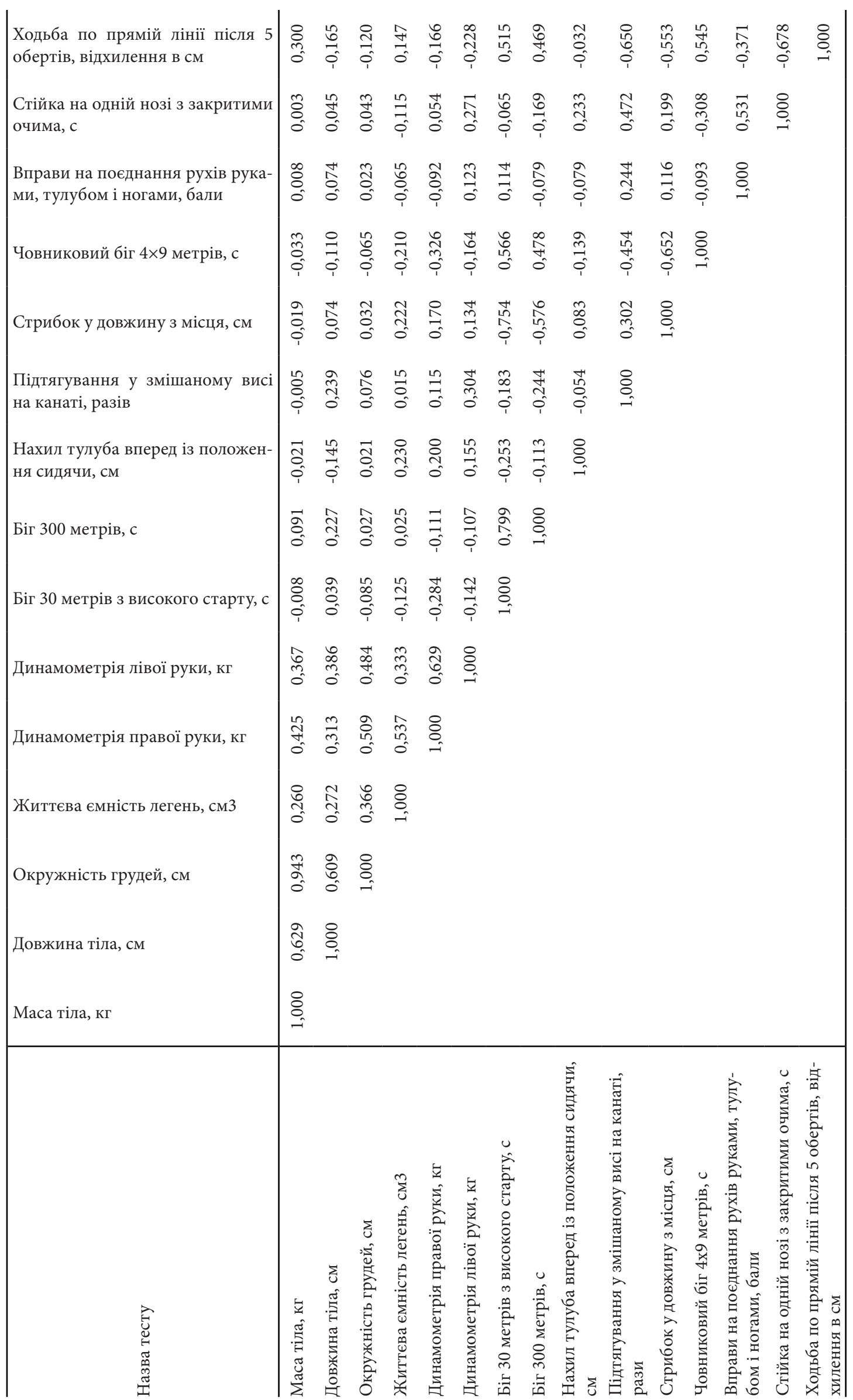


ISSN 2708-7581 (Online). ISSN-L 2708-7573. Journal of Learning Theory and Methodology. 2021. Volume 2, Number 1

Таблиця 3. Пояснена сукупна дисперсія

\begin{tabular}{cccccccccc}
\hline \multirow{2}{*}{$\mathbf{N}$} & \multicolumn{3}{c}{ Початкові власні значення } & \multicolumn{3}{c}{ Витяг суми квадратів навантажень } & \multicolumn{2}{c}{ Ротація суми квадратів навантажень } \\
\cline { 2 - 9 } & Всього & \% дисперсії & Сумарний \% & Всього & \% дисперсії & Сумарний \% & Всього & \% дисперсії & Сумарний \% \\
\hline 1 & 4,332 & 28,882 & 28,882 & 4,332 & 28,882 & 28,882 & 3,364 & 22,423 & 22,423 \\
2 & 3,120 & 20,798 & 49,679 & 3,120 & 20,798 & 49,679 & 3,189 & 21,263 & 43,686 \\
3 & 1,997 & 13,314 & 62,993 & 1,997 & 13,314 & 62,993 & 2,484 & 16,558 & 60,245 \\
4 & 1,262 & 8,414 & 71,408 & 1,262 & 8,414 & 71,408 & 1,674 & 11,163 & 71,408 \\
\hline
\end{tabular}

ня вестибулярної стійкості $(\mathrm{r}=-0,650)$. Швидкісно-силові здібності мають негативний вплив на здібність до диференціювання просторово-часових параметрів рухів $(\mathrm{r}=-0,652)$ та здібність до збереження вестибулярної стійкості $(\mathrm{r}=-0,553)$.

Також у результаті кореляційного аналізу встановлено особливості взаємозв'язку між показниками тестів «Човниковий біг $4 \times 9$ метрів» і «Ходьба по прямій лінії після 5 обертів» $(\mathrm{r}=0,545)$.

Виявлено позитивний кореляційний зв'язок між показниками здібності до координованості рухів і здібності до збереження стійкості пози $(\mathrm{r}=0,531)$. Здібність до збереження стійкості пози негативно корелює зі здібністю до збереження вестибулярної стійкості $(\mathrm{r}=-0,678)$.

Кореляційний аналіз свідчить про те, що гнучкість практично не впливає на антропометричні показники та показники, що характеризують розвиток інших рухових здібностей (швидкість, сила, витривалість, рівновага). Для визначення структури морфофункціональної і рухової підготовленості хлопчиків 8 років був проведений факторний аналіз по 15 показникам тестування. Результати аналізу наведені в таблицях 3-4. У процесі аналізу виділилось чотири фактори які пояснюють 71,408\% сумарної дисперсії показників (табл. 3).

Перший фактор можна інтерпретувати як фактор комплексного прояву провідних рухових здібностей, так як в нього з високими вагами увійшли показники, що характеризують стан рухової сфери з різних сторін. Фактор має найбільшу інформативність (22,423\%). Він корелює з результатами «Біг 30 метрів з високого старту» (,927), «Стрибок у довжину з місця» $(-, 854)$, «Біг 300 метрів» (,826), «Човниковий біг 4x9 метрів» (,735). Фактор отримав назву комплексний.

Наступний за величиною вкладу в сумарну дисперсію вибірки другий фактор (інформативність 21,263\%) був ідентифікований як фактор антропометричних відмінностей. Він корелює з результатами «Окружність грудей» (,908), «Маса тіла» (,893), «Довжина тіла» $(, 819)$.

Третій фактор (інформативність 16,558\%) корелює 3 результатами «Стійка на одній нозі з закритими очима» $(, 886)$, «Вправи на поєднання рухів руками, тулубом і ногами» $(, 728)$, «Ходьба по прямій лінії після 5 обертів» (-,702), «Підтягування у змішаному висі на канаті» (,652). Фактор отримав назву координація рухів і силова підготовленість.

Фактор 4 корелює з результатами «Нахил тулуба вперед із положення сидячи» $(, 809)$ і характеризує гнучкість. Його внесок в загальну дисперсію вибірки становить $11,163 \%$.

Аналіз спільностей указує, що запропонована батарея тестів $є$ інформативною (табл. 4). Найбільшу інформативність для комплексної оцінки перспективності
Таблиця 4. Повернута матриця компонентіва

\begin{tabular}{|c|c|c|c|c|c|}
\hline \multirow{2}{*}{ Назва тесту } & \multicolumn{4}{|c|}{ Компонент } & \multirow{2}{*}{$\mathbf{h}^{2}$} \\
\hline & 1 & 2 & 3 & 4 & \\
\hline Біг 30 метрів з високого старту, с & ,927 & & & & ,889 \\
\hline Стрибок у довжину з місця, см &,- 854 & & & & ,748 \\
\hline Біг 300 метрів, с & ,826 & & & & ,708 \\
\hline Човниковий біг $4 \times 9$ метрів, с & ,735 & & & & 638 \\
\hline Окружність грудей, см & & ,908 & & & ,839 \\
\hline Маса тіла, кг & & ,893 & & & ,801 \\
\hline Довжина тіла, см & & ,819 & & & ,707 \\
\hline Динамометрія лівої руки, кг & & & & & ,614 \\
\hline $\begin{array}{l}\text { Стійка на одній нозі з закритими } \\
\text { очима, с }\end{array}$ & & & ,886 & & ,834 \\
\hline $\begin{array}{l}\text { Вправи на поєднання рухів ру- } \\
\text { ками, тулубом і ногами, бали }\end{array}$ & & & ,728 & &, 543 \\
\hline $\begin{array}{l}\text { Ходьба по прямій лінії після } 5 \\
\text { обертів, відхилення в см }\end{array}$ & & &,- 702 & & ,855 \\
\hline $\begin{array}{l}\text { Підтягування у змішаному висі } \\
\text { на канаті, разів }\end{array}$ & & & ,652 & &, 571 \\
\hline $\begin{array}{l}\text { Нахил тулуба вперед із положен- } \\
\text { ня сидячи, см }\end{array}$ & & & & 809 & ,698 \\
\hline Життєва місткість легень, см ${ }^{3}$ & & & & &, 561 \\
\hline Динамометрія правої руки, кг & & & & & ,705 \\
\hline
\end{tabular}

Метод виділення факторів: метод головних компонент Метод обертання: варімакс з нормалізацією Кайзера а. Обертання зійшлося за 6 ітерацій

дітей під час відбору для занять у спортивній секції карате мають результати тестів: «Біг 30 метрів з високого старту» $(, 889)$, «Стрибок у довжину з місця» $(, 748)$, «Окружність грудей» $(, 839)$, «Маса тіла» $(, 801)$, «Стійка на одній нозі з закритими очима» $(, 834)$, «Ходьба по прямій лінії після 5 обертів» (,855). Отже, у факторній моделі комплексної оцінки перспективності дітей виділяються антропометричні показники та процеси розвитку швидкісних, швидкісно-силових та координаційних здібностей.

Для наочного відображення достатнього числа факторів у роботі було використано графік власних значень факторів, розташованих у порядку убування (Графічне зображення критерію «Кам'янистий осип» Р. Кеттелла), на якому візуально визначається точка де убування власних значень уповільнюється найбільш сильно (рис. 1).

\section{Дискусія}

Допускалось, що запропонована нами батарея тестів дасть можливість комплексно оцінити рівень перспективності хлопчиків 8 років на етапі початкової спортивної підготовки в секції кіокушинкай карате. У результаті 


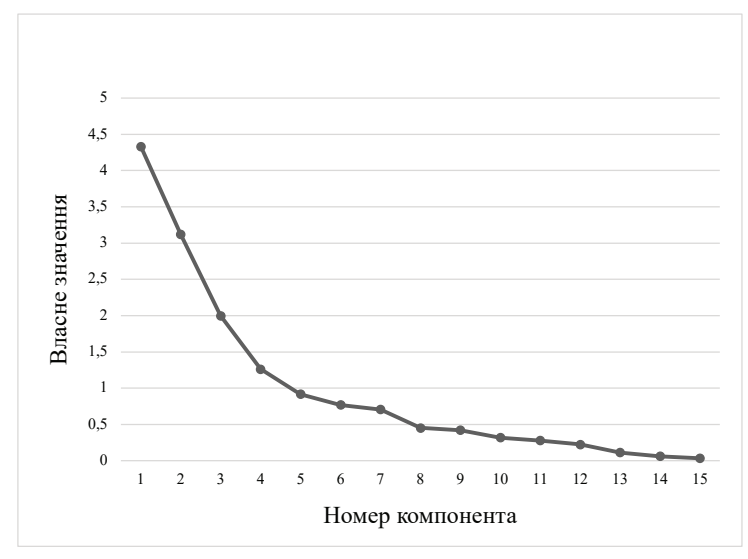

Рис. 1. Графік власних значень

аналізу кореляційної залежності між тестовими завданнями встановлено їх високу інформативність.

Наведені дані доповнюють результати досліджень рівня фізичного розвитку (Марченко, 2006; Марченко \& Іванов, 2011; Podrigalo, Iermakov, \& Jagiello, 2017) та фiзичної підготовленості школярів молодших класів (Марченко, 2007; Марченко \& Іщенко, 2016; Ma \& Qu, 2017 та інші).

Розширюють знання про важливість біологічного розвитку організму дитини, що дає можливість оцінити адаптаційні потенціали для прогнозування успіху та спортивної майстерності (Müller, Müller, Hildebrandt, Kapelari, Raschner, 2015; Podrigalo, Iermakov, \& Jagiello, 2017).

Результати наукових досліджень показують, що спостерігається тенденція дефіциту рухової активності, рівень рухової підготовленості учнів низький (Марченко, 2008; Pavlova, Vynogradskyi, Ripak, Zikrach, \& Borek, 2016 та інші). Отримані нами середні показники підтвердили, що за більшістю рухових тестів, що порівнювались 3 державними тестами і нормативами оцінки фізичної підготовленості населення України (Марченко, 2007; Сергіенко, 2010), хлопчики 8 років мають середній, нижче середнього та низький бали.

Своєю роботою ми прагнули підтвердити знання про важливе значення контролю на початкових етапах відбору дітей, які практикують одноборства і бойові мистецтва (Chaabène, Hachana, Franchini, Mkaouer, Montassar, \& Chamari, 2012; Сергієнко, 2013; Марченко \& Вердиш, 2021). Надійний контроль дасть можливість краще управляти тренувальним процесом та підібрати адекватні засоби для розвитку рухових здібностей з метою планування оптимальної рухової підготовки, яка $є$ базою для навчання технічним діям хлопчиків 8 років які будуть займатися в секції з кіокушинкай карате в позаурочний час.

Результати проведеного експерименту підтверджують, що на етапі початкового відбору перевагу слід віддавати простим педагогічним тестам, які характеризують загальну рухову підготовленість. Особливу увагу слід приділяти тестам, що оцінюють швидкісні якості, координаційні здібності, витривалість (Jagiello, 2000; Марченко \& Поручіков, 2011; Марченко \& Безпалько, 2020) та антропометричні вимірювання (Müller, Müller, Hildebrandt, Kapelari, Raschner, 2015; Podrigalo, Iermakov,
\& Jagiello, 2017), які можна використовувати в якості критерію відбору юних спортсменів для занять карате.

Отримані результати співпадають с даними Ruud J.R. Den Hartigh, A. Susan M. Niessen, Wouter G.P. Frencken \& Rob R. Meijer (2018), Khudolii, Kapkan, Harkusha, Marchenko, \& Veremeenko (2020), Марченко \& Коваленко (2020), Марченко \& Тараненко (2020), що вирішальне значення для результатів відбору та подальшого навчання техніці вправ у фізичному вихованні та спорті має прогнозування.

Новими даними $є$ те, що у факторній моделі комплексної оцінки перспективності хлопців 8 років у процесі відбору на початковому етапі спортивної підготовки пріоритетне місце займають антропометричні показники та процеси розвитку швидкісних, швидкісно-силових та координаційних здібностей.

\section{Висновки}

За результатами нашого дослідження ми можемо стверджувати, що $є$ велика кількість українських і зарубіжних наукових статей, присвячених різним аспектам спортивного відбору. Однак виявлено дефіцит об’єктивної інформації щодо початкового відбору в кіокушинкай карате. Відсутні матеріали про організацію і критерії відбору дітей у секції карате.

Аналіз наукових робіт дозволяє зробити висновок, що первинний рівень фізичної переваги деяких молодих людей над своїми однолітками на момент відбору в спортивні секції та школи не може бути об’єктивним показником високих спортивних результатів у майбутньому. У карате кіокушинкай рекомендовано набирати дітей в 6 річному віці. При роботі з ними не надавати суворої спортивної вузькоспеціалізованої направленості. Проводити відбір комплексно, спираючись на медико-біологічні, педагогічні та психологічні аспекти.

У факторній структурі комплексної оцінки перспективності хлопців 8 років у процесі відбору на початковому етапі пріоритетне місце займають процеси розвитку швидкісних, швидкісно-силових та координаційних здібностей та антропометричні показники.

Найбільшу інформативність для комплексної оцінки перспективності дітей під час відбору для занять у спортивній секції карате мають результати тестів: «Біг 30 метрів з високого старту» $(, 889)$, «Стрибок у довжину 3 місця» (,748), «Окружність грудей» $(, 839)$, «Маса тіла» (,801), «Стійка на одній нозі з закритими очима» $(, 834)$, «Ходьба по прямій лінії після 5 обертів» $(, 855)$.

Перспективою подальших розвідок $є$ вивчення факторної структури комплексної оцінки доцільності подальшого спортивного удосконалення в даному виді спорту хлопців на початковому етапі підготовки. Потребує детального дослідження оцінка задатків і здібностей, сильних і слабких сторін техніко-тактичної майстерності, функціональної підготовленості, рівня розвитку рухових здібностей, психічних особливостей.

\section{Конфлікт інтересів}

Автори заявляють про відсутність конфлікту інтересів. 


\section{Література}

Den Hartigh, R. J. R., Niessen, A. S. M., Frencken, W. G. P., \& Meijer, R. R. (2018). Selection procedures in sports: Improving predictions of athletes' future performance. European Journal of Sport Science, 18(9), 1191-1198. https://doi.org/10.1080/17461391.2018.1480662

Ivashchenko, O. (2020). Research Program: Modeling of Motor Abilities Development and Teaching of Schoolchildren. Teoriâ ta Metodika Fizičnogo Vihovannâ, 20(1), 32-41. https://doi.org/10.17309/tmfv.2020.1.05

Khudolii, O., Ivashchenko, O., Iermakov, S., Nosko, Y., \& Marchenko, S. (2019). Strength Abilities: Estimation of Immediate Training Effect of Strength Loads in Girls Aged 7 Years. Teoria ta Metodika Fizičnogo Vihovanna, 19(2), 98-104. https://doi.org/10.17309/tmfv.2019.2.06

Марченко, С., \& Коваленко, К. (2020). Оптимізація режиму навчання техніки прямого удару ногою «має гері» в кіокушинкай карате хлопців 10 років. Журнал теорії та методології навчання, 1(1), 33-39. https://doi.org/10.17309/jltm.2020.1.05

Cynarski, W. J. (2019). General canon of the philosophy of karate and taekwondo. Ido Movement for Culture, 19(3), 24-32. Scopus. https://doi.org/10.14589/ido.19.3.3

Cynarski, W. J., \& Niewczas, M. (2019). Attitude towards karate among the members of the Polish Cadet representationdiagnostic survey. Ido Movement for Culture, 19(2), 29-35. Scopus. https://doi.org/10.14589/ido.19.2.5

Augustovicova, D., Argajova, J., Rupcik, L., \& Thomson, E. (2020). Development of a reliable and valid kata performance analysis template. Journal of Physical Education and Sport, 20(6), 3553-3559. Scopus. https://doi.org/10.7752/jpes.2020.06479

Platonov, V. (2018). Theoretical and methodological background for sports selection and orientation in modern elite sports. Science in Olympic Sport, 18(3), 2451. https://doi.org/10.32652/olympic2018.3_3

«Про затвердження Рекомендацій щодо стратегічного розвитку фізичного виховання та спортивної підготовки серед учнівської молоді на період до 2025 року»: Наказ Міністерства освіти і науки України від15 лютого 2021 року № 194. Режим доступу до pecypcy: https://zakon.rada.gov.ua/rada/show/v019472921\#Text

Ашмарин, Б.А. (1978). Методика педагогических исследований в физическом воспитании. Л.: ЛГПИ им. Герцена, 142.

Круцевич, Т.Ю. (1985). Научные исследования в массовой физической культуре. К.: Здоров'я, 30-35.

Худолій, О.М., Іващенко, О.В. (2004). Концептуальні підходи до розробки програми наукових досліджень у фізичному вихованні. Теорія та методика фбізичного виховання (4). 2-5.

https://doi.org/10.17309/tmfv.2004.4.140

Бунак, В.В. (1941). Антропометрия. Практический курс. М.: Учпедгдиз, 368.

Марченко, С. (2007). Особливості рухової підготовленості молодших школярів. Teoriâ ta Metodika Fizičnogo Vihovannâ, (5), 15-18, 35, 36. Retrieved from https://www. tmfv.com.ua/journal/article/view/307

Сергієнко, Л.П. (2010). Спортивна метрологія : теорія $i$ практичні аспекти. К.: КНТ, 776.

\section{References}

Den Hartigh, R. J. R., Niessen, A. S. M., Frencken, W. G. P., \& Meijer, R. R. (2018). Selection procedures in sports: Improving predictions of athletes' future performance. European Journal of Sport Science, 18(9), 1191-1198. https://doi.org/10.1080/17461391.2018.1480662

Ivashchenko, O. (2020). Research Program: Modeling of Motor Abilities Development and Teaching of Schoolchildren. Teoriâ ta Metodika Fizičnogo Vihovannâ, 20(1), 32-41. https://doi.org/10.17309/tmfv.2020.1.05

Khudolii, O., Ivashchenko, O., Iermakov, S., Nosko, Y., \& Marchenko, S. (2019). Strength Abilities: Estimation of Immediate Training Effect of Strength Loads in Girls Aged 7 Years. Teoria ta Metodika Fizičnogo Vihovanna, 19(2), 98-104. https://doi.org/10.17309/tmfv.2019.2.06

Marchenko, S., \& Kovalenko, K. (2020). Optimization of Teaching Boys Aged 10 Mae-Geri (Front Kick) Technique in Kyokushin Karate. Journal of Learning Theory and Methodology, 1(1), 33-39. https://doi.org/10.17309/jltm.2020.1.05

Cynarski, W. J. (2019). General canon of the philosophy of karate and taekwondo. Ido Movement for Culture, 19(3), 24-32. Scopus. https://doi.org/10.14589/ido.19.3.3

Cynarski, W. J., \& Niewczas, M. (2019). Attitude towards karate among the members of the Polish Cadet representationdiagnostic survey. Ido Movement for Culture, 19(2), 29-35. Scopus. https://doi.org/10.14589/ido.19.2.5

Augustovicova, D., Argajova, J., Rupcik, L., \& Thomson, E. (2020). Development of a reliable and valid kata performance analysis template. Journal of Physical Education and Sport, 20(6), 3553-3559. Scopus. https://doi.org/10.7752/jpes.2020.06479

Platonov, V. (2018). Theoretical and methodological background for sports selection and orientation in modern elite sports. Science in Olympic Sport, 18(3), 2451. https://doi.org/10.32652/olympic2018.3_3

"Pro zatverdzhennia Rekomendatsii shchodo stratehichnoho rozvytku fizychnoho vykhovannia ta sportyvnoi pidhotovky sered uchnivskoi molodi na period do 2025 roku": Nakaz Ministerstva osvity i nauky Ukrainy vid15 liutoho 2021 roku № 194. Rezhym dostupu do resursu: https://zakon.rada.gov.ua/rada/show/v0194729-21\#Text

Ashmarin, B.A. (1978). Metodika pedagogicheskikh issledovanii $\mathrm{v}$ fizicheskom vospitanii. L.: LGPI im. Gertcena, 142.

Krutcevich, T.Iu. (1985). Nauchnye issledovaniia v massovoi fizicheskoi kulture. K.: Zdorov'ia, 30-35.

Khudolii, O.M., Ivashchenko, O.V. (2004). Kontseptualni pidkhody do rozrobky prohramy naukovykh doslidzhen u fizychnomu vykhovanni. Teoria ta Metodika Fizičnogo Vihovanna, (4). 2-5. https://doi.org/10.17309/tmfv.2004.4.140

Bunak, V.V. (1941). Antropometriia. Prakticheskii kurs. M.: Uchpedgdiz, 368.

Marchenko, S. (2007). Osoblyvosti rukhovoi pidhotovlenosti molodshykh shkoliariv. Teoriâ ta Metodika Fizičnogo Vihovannâ, (5), 15-18, 35, 36. Retrieved from https://www. tmfv.com.ua/journal/article/view/307

Serhiienko, L.P. (2010). Sportyvna metrolohiia : teoriia i praktychni aspekty. K.: KNT, 776. 
Марченко, С., \& Безпалько, Д. (2020). Контроль і оцінка координаційних здібностей хлопчиків 7 років на етапі початкової підготовки в кіокушинкай карате. Журнал теорії та методологї навчання, 1(2), 82-88. https://doi.org/10.17309/jltm.2020.2.06

Марченко, С. (2006). Вікові особливості фізичного розвитку молодших школярів. Teoriâ ta Metodika Fizičnogo Vihovannâ, (6), 9-14. Retrieved from https:// www.tmfv.com.ua/journal/article/view/257

Марченко, С., \& Іванов, В. (2011). Оцінка фізичного розвитку хлопчиків 6-10 років у контексті сучасних завдань фізичного виховання. Teoriâ ta Metodika Fizičnogo Vihovannâ, (8), 10-13. Retrieved from https:// www.tmfv.com.ua/journal/article/view/730

Podrigalo, L.V., Iermakov, S.S., \& Jagiello, W. (2017). Special indices of body composition as a criterion of somatic development of martial arts practitioners. Archives of budo science of martial arts and extreme sports, 17(13), 5-12.

Марченко, С., \& Іщенко, В. (2016). Методика розвитку сили у хлопчиків молодшого шкільного віку засобами рухливих ігор. Теорія та методика фізичного виховання, (3), 19-27. https://doi.org/10.17309/tmfv.2016.3.1167

Ma, A.W.W., \& Qu, L.H. (2017). Effects of Karate Training on Basic Motor Abilities of Primary School Children. Advances in Physical Education, (7), 130-139. https://doi.org/10.4236/ape.2017.72012

Müller, L., Müller, E., Hildebrandt, C., Kapelari, K., \& Raschner, C. (2015). Die Erhebung des biologischen Entwicklungsstandes für die Talentselektion - welche Methode eignet sich? Sportverletz Sportschaden, 29(01), 56-63. https://doi.org/10.1055/s-0034-1399043

Марченко, C.I. (2008). Характеристика впливу ігрових засобів на динаміку розвитку швидкісно-силових здібностей учнів молодшого шкільного віку. Теорія та методика фізичного виховання, 8(1), 29-34.https:// www.tmfv.com.ua/journal/article/view/390

Pavlova, Iu., Vynogradskyi, B., Ripak, I., Zikrach, D., \& Borek, Z. (2016). Prognostication of health-related life quality of Ukrainian residents due to physical activity level. Journal of Physical Education and Sport (JPES), 16(2), Art. 65: 418423. https://doi.org/10.7752/jpes.2016.02065

Chaabène, H., Hachana, Y., Franchini, E., Mkaouer, B., Montassar, M., \& Chamari, K. (2012). Reliability and Construct Validity of the Karate-Specific Aerobic Test. Journal of Strength and Conditioning Research, 26(12), 3454-3460. https://doi.org/10.1519/JSC.0b013e31824eddda

Сергиенко, Л.П. (2013). Спортивный отбор: теория и практика: монография [Текст]. М. : Советский спорт, 1048.

Марченко, С., \& Вердиш, Я. (2021). Оцінка надійності та інформативності показників координаційної підготовленості хлопчиків 8 років. Журнал теорії та методології навчання, 2(1), 21-28. https://doi.org/10.17309/jltm.2021.1.03

Jagiello, W. (2000). Przygotowanie fizyczne mlodego sportowca. Biblioteka Trenera. Centralny Osrodek Sportu, Warszawa, 203.

Марченко, С., \& Поручіков, В. (2011). Оцінка рухової підготовленості хлопчиків молодших класів. Теорія ma методика фізичного виховання, (7), 14-17. Retrieved iз https://tmfv.com.ua/journal/article/view/723
Marchenko, C., \& Bezpalko, Д. (2020). Control and Assessment of 7-Year-Old Boys' Coordination Abilities at the Initial Training Stage in Kyokushin Karate. Journal of Learning Theory and Methodology, 1(2), 82-88. https://doi. org/10.17309/jltm.2020.2.06

Marchenko, S. (2006). Vikovi osoblyvosti fizychnoho rozvytku molodshykh shkoliariv. Teoriâ ta Metodika Fizičnogo Vihovannâ, (6), 9-14. Retrieved from https://www.tmfv. com.ua/journal/article/view/257

Marchenko, S., \& Ivanov, V. (2011). Otsinka fizychnoho rozvytku khlopchykiv 6-10 rokiv u konteksti suchasnykh zavdan fizychnoho vykhovannia. Teoriâ ta Metodika Fizičnogo Vihovannâ, (8), 10-13. Retrieved from https:// www.tmfv.com.ua/journal/article/view/730

Podrigalo, L.V., Iermakov, S.S., \& Jagiello, W. (2017). Special indices of body composition as a criterion of somatic development of martial arts practitioners. Archives of budo science of martial arts and extreme sports, 17(13), 5-12.

Marchenko, S., \& Ishchenko, V. (2016). Metodyka rozvytku syly u khlopchykiv molodshoho shkilnoho viku zasobamy rukhlyvykh ihor. Teoriâ ta Metodika Fizičnogo Vihovannâ, (3), 19-27. https://doi.org/10.17309/tmfv.2016.3.1167

Ma, A.W.W., \& Qu, L.H. (2017). Effects of Karate Training on Basic Motor Abilities of Primary School Children. Advances in Physical Education, (7), 130-139. https://doi.org/10.4236/ape.2017.72012

Müller, L., Müller, E., Hildebrandt, C., Kapelari, K., \& Raschner, C. (2015). Die Erhebung des biologischen Entwicklungsstandes für die Talentselektion - welche Methode eignet sich? Sportverletz Sportschaden, 29(01), 56-63. https://doi.org/10.1055/s-0034-1399043

Marchenko, S.I. (2008). Kharakterystyka vplyvu ihrovykh zasobiv na dynamiku rozvytku shvydkisno-sylovykh zdibnostei uchniv molodshoho shkilnoho viku. Teoriâ ta Metodika Fizičnogo Vihovannâ, 8(1), 29-34.https://www. tmfv.com.ua/journal/article/view/390

Pavlova, Iu., Vynogradskyi, B., Ripak, I., Zikrach, D., \& Borek, Z. (2016). Prognostication of health-related life quality of Ukrainian residents due to physical activity level. Journal of Physical Education and Sport (JPES), 16(2), Art. 65: 418423. https://doi.org/10.7752/jpes.2016.02065

Chaabène, H., Hachana, Y., Franchini, E., Mkaouer, B., Montassar, M., \& Chamari, K. (2012). Reliability and Construct Validity of the Karate-Specific Aerobic Test. Journal of Strength and Conditioning Research, 26(12), 3454-3460. https://doi.org/10.1519/JSC.0b013e31824eddda

Sergienko, L.P. (2013). Sportivnyi otbor: teoriia i praktika: monografiia [Tekst]. M. : Sovetskii sport, 1048.

Marchenko, S., \& Verdysh, Ya. (2021). Assessment of Reliability and Informativeness of Coordination Fitness Indicators of 8-Year-Old Boys. Journal of Learning Theory and Methodology, 2(1), 21-28. https://doi.org/10.17309/ jltm.2021.1.03

Jagiello, W. (2000). Przygotowanie fizyczne mlodego sportowca. Biblioteka Trenera. Centralny Osrodek Sportu, Warszawa, 203.

Marchenko, S., \& Poruchikov, V. (2011). Otsinka rukhovoi pidhotovlenosti khlopchykiv molodshykh klasiv. Teori $\hat{a}$ ta Metodika Fizičnogo Vihovannâ, (7), 14-17. Retrieved i3 https://tmfv.com.ua/journal/article/view/723 
Khudolii, O., Kapkan, O., Harkusha, S., Marchenko, S., \& Veremeenko, V. (2020). Motor Skills Development: Optimization of Teaching Boys Aged 15 Press Headstand and Handstand. Teoriâ ta Metodika Fizičnogo Vihovannâ, 20(1), 42-48. https://doi.org/10.17309/tmfv.2020.1.06

Marchenko, S., \& Taranenko, O. (2020). Керування ефективністю навчання техніки колового удару ногою «маваші гері» у кіокушинкай карате хлопців 10 років. Теорія та методика фізичного виховання, 20(4), 262268. https://doi.org/10.17309/tmfv.2020.4.10
Khudolii, O., Kapkan, O., Harkusha, S., Marchenko, S., \& Veremeenko, V. (2020). Motor Skills Development: Optimization of Teaching Boys Aged 15 Press Headstand and Handstand. Teoriâ ta Metodika Fizičnogo Vihovannâ, 20(1), 42-48. https://doi.org/10.17309/tmfv.2020.1.06

Marchenko, S., \& Taranenko, O. (2020). Managing the Effectiveness of Teaching Boys Aged 10 Mawashi-Geri (Roundhouse Kick) Technique in Kyokushin Karate. Teoriâ ta Metodika Fizičnogo Vihovannâ, 20(4), 262-268. https://doi.org/10.17309/tmfv.2020.4.10

\title{
ORGANIZATION OF SELECTION TO KYOKUSHIN KARATE SPORTS SECTION
}

\author{
Sofia Mukhina ${ }^{1 \mathrm{ABCD}}$, Svitlana Marchenko ${ }^{1 \mathrm{ABCD}}$
}

\author{
${ }^{1}$ H. S. Skovoroda Kharkiv National Pedagogical Universityи
}

Authors' Contribution: A - Study design; B - Data collection; C - Statistical analysis; D - Manuscript Preparation; E - Funds Collection Report. Article: 6 p., 4 tabl., 1 fig., 34 sources.

Purpose. To determine a factor model of morphofunctional and motor fitness of 8 -year-old boys at the stage of initial selection to a Kyokushin Karate sports section.

Materials and methods. The study involved 32 8-year-old boys. The children and their parents were informed about all the features of the study and gave their consent to participate in the experiment. To solve the tasks set, the following research methods were used: theoretical analysis and generalization of scientific and methodological literature data; pedagogical observation; timing of training tasks; pedagogical testing; methods of mathematical and statistical data processing.

Results. The study obtained a factor model of a comprehensive assessment of 8-year-old boys' prospects during selection at the initial stage of sports training. The analysis of correlation dependence between the test tasks showed their high informativeness. Anthropometric indicators and processes of development of speed, speed-strength, and coordination abilities occupy a priority place in the factor structure.

Conclusions. The results of tests: " $30 \mathrm{~m}$ running from a standing start" (0.889), "Standing long jump" (0.748), "Chest girth" (0.839), "Body weight" (0.801), "Standing on one leg with closed eyes" (0.834), "Walking along straight line after 5 rotations" (0.855) are most informative for a comprehensive assessment of children's prospects during selection for training at the karate sports section.

Keywords: boys, selection, morphofunctional fitness, motor fitness, factor analysis, karate.

\section{Information about the authors:}

Mukhina Sofia: sofiya.muhina3@gmail.com; https://orcid.org/0000-0002-8715-6715; H. S. Skovoroda Kharkiv National Pedagogical University, Alchevskykh St, 29, Kharkiv, 61002, Ukraine.

Marchenko Svitlana: sport-svet1968@ukr.net; https://orcid.org/0000-0002-1013-9511;H. S. Skovoroda Kharkiv National Pedagogical University, Department of Theory and Methodology of Physical Education, Alchevskykh St, 29, Kharkiv, 61002, Ukraine.

Cite this article as: Mukhina, S. \& Marchenko, S. (2021). Organization of Selection to Kyokushin Karate Sports Section. Journal of Learning Theory and Methodology, 2(1), 33-40. https://doi.org/10.17309/jltm.2021.1.05

Received: 27.01.2021. Accepted: 20.02.2021. Published: 26.02.2021

This work is licensed under a Creative Commons Attribution 4.0 International License (http://creativecommons.org/licenses/by/4.0). 